\title{
O CONTEXTO ATUAL DA EDUCAÇÃO DO CAMPO: O QUE DIZEM AS PESQUISAS REALIZADAS
}

\author{
Ana Sara Castaman ${ }^{1}$ \\ Josimar de Aparecido Vieira ${ }^{2}$ \\ Cristiane Longaray Radke ${ }^{3}$
}

\section{Resumo}

Este ensaio apresenta, em linhas gerais, uma leitura crítica e analítica acerca do contexto da educação do campo na atualidade por meio da realização de um inventário das produções bibliográficas disponibilizadas. A metodologia empregada remete a um estudo qualitativo do estado do conhecimento sobre pesquisas que tratam da educação do campo tendo como principal fonte os dados disponíveis nas publicações da ANPED - Associação Nacional de Pesquisa em Educação, relativas às reuniões que são realizadas anualmente. Foram envolvidos os trabalhos do GT 03 Movimentos Sociais e Educação (anos 2010 e 2011) e GT 03 Movimentos Sociais, Sujeitos e Processos Educativos (anos 2012 a 2015), relativos à 33은 a 37ํㅜ reunião que estão disponibilizados na home page do evento. Analisou-se setenta e três trabalhos desses GTs sendo selecionados 35 por abordarem questões relacionadas com a educação do campo. A partir dos dados inventariados e de aportes de pesquisadores que se ocupam com a educação do campo, este trabalho foi organizado em três partes onde é analisado o contexto da educação do campo na atualidade, com destaques para as contribuições da educação do campo para o desenvolvimento territorial, as relações entre os movimentos sociais e reformas agrárias e a formação dos professores envolvidos nesta modalidade de ensino e na formação dos estudantes para o trabalho. Constatou-se que a educação do campo tem o desafio de elaborar projetos educativos que permitam aos povos do campo o desenvolvimento sustentável e o crescimento social; promover políticas para romper com o processo de discriminação adotando um desenho curricular orientado para a formação das pessoas que vivem no campo e retomar urgentemente políticas de incentivos e subsídios aos pequenos produtores rurais tendo em vista o processo de globalização e precarização do mundo do trabalho.

Palavras-chave: Educação do campo, Desenvolvimento territorial, Formação de professores.

\footnotetext{
${ }^{1}$ Possui mestrado em Educação Nas Ciências pela Universidade Regional do Noroeste do Estado do Rio Grande do Sul (2006) e doutorado em Educação pela Universidade do Vale do Rio dos Sinos (2011). Atualmente é professora no Instituto Federal do Rio Grande do Sul.

${ }^{2}$ Doutorado em Educação pela Pontifícia Universidade Católica do Rio Grande do Sul - PUCRS (2011). Atualmente é Professor de Ensino Básico, Técnico e Tecnológico da área de Pedagogia do Instituto Federal de Educação, Ciência e Tecnologia do Rio Grande do Sul (IFRS) - Campus Sertão.

${ }^{3}$ Possui graduação em Ciências Contábeis pela Universidade de Passo Fundo(2001), especialização em Teorias e Metodologia da Educação (Lato Sensu) pelo Instituto Federal de Educação, Ciência e Tecnologia do Rio Grande do Sul(2016)

Criar Educação, Criciúma, v. 7, n¹, jan/jul 2018.- PPGE - UNESC
} 


\title{
THE CURRENT CONTEXT OF FIELD EDUCATION: WHAT SAY PERFORMED RESEARCHES
}

\begin{abstract}
This essay presents, in general lines, a critical and analytical reading about the context of field education in the present time through the accomplishment of an inventory of the bibliographic productions available. The methodology used refers to a qualitative study of the state of knowledge about researches that deals with the field education, having as main source the data available in the publications of ANPED - National Association of Research in Education, concerning the meetings that are held annually. Are involved the works of GT 03 Social Movements and Education (years 2010 and 2011) and GT 03 Social Movements, Subjects and Educational Processes (years 2012 to 2015), related to the 33rd to 37th meetings that are available on the home page of the event. Seventy-three studies of these GTs were analyzed and 35 were selected for addressing issues related to field education. Based on the inventoried data and the contributions of researchers who are involved in field education, this work was organized in three parts, where the context of field education in actuality is analyzed, with highlights for the contributions of field education to the territorial development, the relations between social movements and agrarian reforms and the formation of teachers involved in this modality of education and the formation of students for work. It was verified that the field education has the challenge of elaborating educational projects that allow to the field people the sustainable development and the social growth; promote policies to break the discrimination process by adopting a curriculum design geared towards the training of people that live in the countryside and urgently resume incentives and subsidies policies to small farmers in view of the process of globalization and precariousness of the world of work.
\end{abstract}

Keywords: Field education, Territorial development, Teacher formation.

\section{INTRODUÇÃO}

A educação do campo vem conquistando cada vez mais espaços de discussões no âmbito municipal, estadual e federal e se mobilizando numa perspectiva mais radical para a humanização das pessoas. Pode-se enfatizar que este movimento atual acompanha a história da educação do campo no Brasil e as mudanças de ordem política, econômica e social, sendo que o seu princípio se deu com as lutas dos movimentos sociais camponeses, em contraponto à educação rural.

Uma das bandeiras do movimento é mostrar que a escola não se constitui como um "lugar de estudo", já que se torna desnecessário estar em uma instituição escolar para aprender. Porém, ela assume "o lugar de formação 
humana" que instiga os sujeitos em almejar instrução, disciplina, cultura e conhecimento. O papel da educação também é o de formar sujeitos críticos, capazes de lutar e arquitetar outro projeto de desenvolvimento para a nação e nela, o contexto do campo (SANTOS; PALUDO; OLIVEIRA, 2010, Grifos nossos).

Esta perspectiva busca a construção de um futuro melhor para todos, assim como o cumprimento do direito de acesso universal à educação e a legitimidade dos processos didáticos localmente significados, adicionados à defesa de um projeto de desenvolvimento social, economicamente justo e ecologicamente sustentável. Neste projeto de desenvolvimento, a escola do campo tem um papel estratégico (BRASIL, 2002). Os territórios compõem inúmeros modelos de desenvolvimento, com organizações espaciais diferentes, paisagens geográficas distintas, portanto a educação do/no campo precisa ser pensada para seu desenvolvimento.

Para isso, os professores desempenham papel preponderante, devendo rever suas posturas como meros transmissores/reprodutores de conteúdos e assumir a docência como formadores/mediadores que compreendem a relevância de instigar o estudante a refletir e transformar o espaço em que está inserido. Desta forma, torna-se necessário o envolvimento das famílias nas escolas, auxiliando e decidindo no seu funcionamento. Os envolvidos nesta dinâmica assumem papel de sujeitos, unidos num movimento maior que pode ser definido como história. Nesta concepção encontram-se pessoas que fazem transformações sociais, mesmo que embaladas pela materialidade das relações em que estão inseridas, e aquelas que se definem pessoalmente.

Diante destas considerações, este ensaio apresenta uma leitura crítica e analítica do contexto atual da educação do campo. Para isso foi realizado o estado do conhecimento sobre pesquisas que tratam da educação do campo tendo como principal fonte os dados disponíveis nas publicações da ANPED - Associação Nacional de Pesquisa em Educação. Inventariou-se as produções disponibilizadas entre os anos de 2010 à 2015 acerca das contribuições da educação do campo para o desenvolvimento territorial, as relações entre os movimentos sociais e reformas agrárias e a formação dos professores envolvidos nesta modalidade de ensino e a formação dos estudantes para o trabalho. 


\title{
2 REFERENCIAL TEÓRICO
}

\subsection{CONTRIBUIÇÕES DA EDUCAÇÃO DO CAMPO AO DESENVOLVIMENTO TERRITORIAL}

Diante do contexto histórico do Brasil em relação à educação do campo, a primeira vez que a educação rural foi contemplada em uma constituição foi em 1934, sendo que esta vigorou por três anos. Como elucida Henriques et. al. (2007, p. 12) a modificação mais expressiva advinda na educação rural foi o movimento nacional desencadeado à construção de uma escola para o campo:

\begin{abstract}
Em 1998, foi criada a "Articulação Nacional por uma Educação do Campo", entidade supra-organizacional que passou a promover e gerir as ações conjuntas pela escolarização dos povos do campo em nível nacional. Dentre as conquistas alcançadas por essa Articulação estão a realização de duas Conferências Nacionais por uma Educação Básica do Campo - em 1998 e 2004, a instituição pelo Conselho Nacional de Educação (CNE) das Diretrizes Operacionais para a Educação Básica nas Escolas do Campo, em 2002; e a instituição do Grupo Permanente de Trabalho de Educação do Campo (GPT), em 2003.
\end{abstract}

Nesta direção, Caldart (2012, p. 257-258) apresenta contribuição que esclarece sobre o surgimento da expressão "Educação do Campo":

O surgimento da expressão 'Educação do Campo' pode ser datado. Nasceu primeiro como Educação Básica do Campo no contexto de preparação da I Conferência Nacional por uma Educação Básica do Campo, realizada em Luziânia, Goiás, de 27 a 30 de julho 1998. Passou a ser chamada Educação do Campo a partir das discussões do Seminário Nacional realizado em Brasília de 26 a 29 de novembro 2002, decisão posteriormente reafirmada nos debates da II Conferência Nacional, realizada em julho.

O principal berço que deu origem a luta pela terra foi empreendida pelo Movimento dos Trabalhadores Rurais Sem Terra (MST) em meados de 1990. Essa ação marcou a concepção de Educação do Campo legitimando a luta por políticas públicas específicas e por um projeto educativo próprio aos sujeitos que vivem e atuam no campo. A concretização desse embasamento estabelece a implementação 
de políticas que abranjam a Educação e a Escola do Campo a partir de alguns princípios que constam nas Referências para uma Política Nacional de Educação do Campo - Caderno Subsídio (2003, p. 32-34), conforme segue:

I. A Educação do Campo de qualidade é um direito dos povos do campo.

II. A Educação do Campo e o respeito às organizações sociais e o conhecimento por elas produzido.

III. A Educação do Campo no campo.

IV. A Educação do Campo enquanto produção de cultura.

V. A Educação do Campo na formação dos sujeitos.

VI. A Educação do Campo como formação humana para o Desenvolvimento Sustentável.

VII. A Educação do Campo e o respeito às características do Campo.

A Educação do Campo compreende um ensino organizado pelos trabalhadores do campo, resultante das lutas organizadas e efetivadas por estes em movimentos sociais populares, com o objetivo de constituir uma educação direcionada ao campesinato. Porém, para garantir o direito de todos os cidadãos, a escola necessita estar alocada no espaço em que as pessoas estão. Estas escolas do campo carecem de uma educação característica de seu cotidiano, baseada em um contexto próprio e voltada aos interesses e às necessidades da população que ali habitam e trabalham.

Nesta direção, a educação do campo é vista como um prática social organicamente vinculada aos demais processos sociais que constituem a dinâmica social, que pode produzir, reproduzir e transformar a sociedade. Como práxis educativa, esta educação deve abranger não somente a escola, mas também as práticas e políticas do desenvolvimento agrário. Para isso, torna-se necessário compreender como se dá a construção e apropriação do saber social pelo camponês na sua vida cotidiana.

[...] o rico tecido da prática social do campesinato constitui o manancial de onde jorra o saber social, que por sua vez realimenta esta prática. Um exame mais cuidadoso da vida real dos camponeses põe em evidência que, quanto à sua origem, o saber social pode ser nucleado em torno de três blocos principais: o saber gerado no processo de trabalho e nas relações de produção; saber produzido na prática política; saber apropriado pelos camponeses através da mediação dos agentes educativos (DAMASCENO, 1992, P. 38). 
Desse ponto de vista, fica demonstrado que o saber do camponês é construído a partir de um aprendizado que se dá na vida cotidiana, por meio de um modo particular, como são organizadas a produção e as relações sociais no trabalho concreto, produto, portanto, do processo de criação e recriação das suas condições de existência material e social (Grzybowski in Damasceno, 1992).

Para o desenvolvimento deste território camponês é impreterível uma política educacional que acolha sua diversidade e amplitude, que reconheça a população do campo como protagonista de políticas e não como receptores e/ou usuários. Os territórios são espaços geográficos e políticos, em que os sujeitos sociais executam seus projetos de vida para o desenvolvimento. Os sujeitos sociais organizam-se por meios das relações de classe para desenvolver seus territórios. No campo, os territórios do campesinato e do agronegócio são organizados de formas distintas, a partir de diferentes classes e relações sociais (FERNANDES, 2012b).

Existem alguns pontos que devem ser considerados no "projeto popular de desenvolvimento do Campo", de acordo com Santos, Paludo e Oliveira (2010, p. 49):

\begin{abstract}
A Soberania Alimentar como princípio organizador de uma nova agricultura, com uma produção voltada para atender as necessidades do povo e com políticas públicas voltadas para esse objetivo; a) a democratização da propriedade e do uso da terra - a Reforma Agrária integral deve voltar à agenda prioritária do país como forma de reverter o processo de expulsão do campo e disponibilizar a terra para a produção de alimentos; b) uma nova matriz produtiva e tecnológica, que combine produtividade do trabalho com sustentabilidade socioambiental, o que inclui a opção pela agroecologia; c) o princípio da cooperação, em lugar da exploração, para organizar a produção; d) a mudança da matriz energética; e) o avanço na organização política, econômica e comunitária dos camponeses e pequenos agricultores.
\end{abstract}

O campo é percebido como um território que une grandezas e permite o desenvolvimento territorial, a partir da sustentabilidade e soberania alimentar, na utilização de práticas agroecológicas. Já a educação para o campo, sob a perspectiva do agronegócio, não serviria a um projeto que atenda aos setores campesinos, pois sua proposta é a formação da força de trabalho difundindo ideologias que contribuem para a perpetuação das desigualdades sociais numa sociedade capitalista. 


\subsection{MOVIMENTOS SOCIAIS E REFORMAS AGRÁRIAS (ASSENTAMENTOS)}

Os movimentos sociais assinalam uma ação prática de grupo ou movimento em defesa de uma classe social, com finalidade de preservação na sociedade. 0 MST é um movimento social que reproduz uma disputa hegemônica e ancora-se nesta perspectiva nos territórios do agronegócio e do campesinato, uma vez que simplificadamente pode significar que o primeiro está pautado na produção para 0 mercado e o segundo na agricultura familiar. Fernandes (2008, p. 40) apresenta uma diferenciação primária nos seguintes termos:

Temos dois campos, porque os territórios do campesinato e os territórios do agronegócio são organizados de formas distintas, a partir de diferentes relações sociais. Um exemplo importante é que enquanto o agronegócio organiza seu território para a produção de mercadorias, o grupo de camponeses organiza seu território, primeiro para sua existência, precisando desenvolver todas as dimensões de sua vida. [...] A paisagem do território do agronegócio é homogênea, enquanto a paisagem do território camponês é heterogênea. A composição uniforme e geométrica da monocultura se caracteriza pela pouca presença de pessoas no território, porque sua área está ocupada por mercadoria, que predomina na paisagem. A mercadoria é a expressão do território do agronegócio. A diversidade dos elementos que compõem a paisagem do território camponês é caracterizada pela grande presença de pessoas no território, porque é nesse e desse espaço que constroem suas existências, produzindo alimentos.

O Movimento dos Trabalhadores Rurais Sem Terra - MST (2017) em seu site na internet, no link "quem somos", trata acerca de seu projeto:

O Movimento Sem Terra está organizado em 24 estados nas cinco regiões do país. No total, são cerca de 350 mil famílias que conquistaram a terra por meio da luta e da organização dos trabalhadores rurais. Mesmo depois de assentadas, estas famílias permanecem organizadas no MST, pois a conquista da terra é apenas o primeiro passo para a realização da Reforma Agrária.

Prossegue no Dicionário Online de Português (2017) o significado de Reforma Agrária: 
Reorganização da estrutura agrícola de um país ou região, através de medidas que buscam equilibrar e promover a melhor distribuição de terras, cumprindo princípios de justiça social, desenvolvimento rural sustentável e crescimento da produção: o INCRA é o órgão governamental responsável pelas medidas relacionadas à Reforma agrária no Brasil.

No site do Instituto Nacional de Colonização e Reforma Agrária - INCRA (2017) que é uma autarquia federal da Administração Pública Brasileira consta o significado e normas para um Assentamento:

Os trabalhadores rurais que recebem o lote comprometem-se a morar na parcela e a explorá-la para seu sustento, utilizando exclusivamente a mão de obra familiar. Além da distribuição de terras, os assentamentos da reforma agrária dão condições de moradia e de produção familiar e garantem a segurança alimentar de brasileiros das zonas rurais que até então se encontravam sob risco alimentar e social. Os assentados pagam pela terra que receberam do Incra e pelos créditos contratados.

Sabemos que a realidade do campo é diversificada, não sendo análoga para todos os povos do campo, no entanto pode ser atrelada de acordo com as necessidades de cada comunidade, localidade e território. Assim, o sujeito que compartilha destes espaços geográficos carece de uma formação que possibilite ao mesmo, explorar as próprias potencialidades, tornando-se cidadão responsável e com habilidades cognitivas que propiciem um aparelhamento para encarar o mundo do trabalho. Em resumo, aprender na escola e fora dela deve fazer parte do mundo do trabalho contemporâneo.

\subsection{FORMAÇÃO DOS PROFESSORES E SEUS CAMPONESES E A INTEGRAÇÃO COM O TRABALHO}

Apesar de a educação campesina lidar com a distinção por longo do tempo, pelo desprezo, pela atuação tardia dos poderes públicos, em meados do século XX ela começa a ser concebida e abordada nas políticas públicas. Na LDB, Lei №. 9.394/96, no art. 28 inciso I, constata-se certa preocupação acerca da oferta da educação nas escolas rurais, antevendo a adaptação dos conteúdos e metodologias às reais demandas e interesses dos estudantes das escolas do campo: 
I - Na oferta de educação básica para a população rural, os sistemas de ensino promoverão as adaptações necessárias à sua adequação às peculiaridades da vida rural e de cada região, especialmente: I - Conteúdos curriculares e metodologias apropriadas às reais necessidades e interesses dos alunos da zona rural (BRASIL, no. 9.394/96, art. 28, inciso I).

No Plano Nacional de Educação - PNE (1998) constata-se a proposta para as escolas do campo receber atenção e tratamento diferenciado, assegurando que o ensino básico contemple a todos.

A escola rural requer um tratamento diferenciado, pois a oferta de ensino fundamental precisa chegar a todos os recantos do País e a ampliação da oferta de quatro séries regulares em substituição às classes isoladas unidocentes é meta a ser perseguida, consideradas as peculiaridades regionais e a sazonalidade.

Este direcionamento para a educação do campo se deve a nova identidade elaborada pelos movimentos sociais de trabalhadores e trabalhadoras do campo, conforme Costa (2004, p. 185):

De modo geral, a identidade pode ser definida ou se caracteriza pela posição na qual os sujeitos se colocam ou são colocados sob o olhar da sociedade. A identidade de um determinado grupo resulta desta forma, tanto da maneira como o grupo vê, simboliza e discursa sobre si, quanto da maneira como a sociedade vê, simboliza e discursa sobre o grupo.

Além disso, os trabalhadores estão resistindo para continuar produzindo num espaço rural, outra justificativa para que se mantenham no interior deve-se a realidade socioeconômica de nosso país, devido a crescente pobreza, o desemprego, as grandes desigualdades sociais e as dificuldades de acesso às políticas públicas (saúde, educação, transporte, infraestrutura etc.). Portanto, pensar um projeto de educação do campo remete em sua sustentabilidade em termos econômicos, sociais e culturais.

Ainda, para Imbernón (2000, p. 12), "[...] a nova era requer um profissional da educação diferente". Dessa forma, educadores precisam estar atentos e preparados para suportar as adversidades e os empecilhos que thes surgirem ao longo do percurso profissional e formativo. $O$ maior desafio, hodierno, para os professores 
além de organizar o ambiente educativo de forma a instigar estes estudantes a desejarem por se educar é de fazer com que eles compreendam a necessidade da aprendizagem, do estudar e de produzir conhecimento, que aprendam como descobrir suas capacidades, formas de expressão e virtudes, de ser mais sensível, como se relacionar com as pessoas, de tornarem-se mais humanos.

Corrobora Arroyo $(2004$, p. 74$)$ quando argumenta que os profissionais da educação precisam compreender os estudantes "[...] Como sujeitos de história, de lutas, como sujeitos de intervenção, como alguém que constrói, que está participando de um projeto social, por isso que a escola tem que levar em conta a história de cada educando e das lutas do campo". A educação do campo se baseia nos princípios da pedagogia socialista que prima pela formação humana integral e emancipatória, atrelada a um projeto histórico que supere a sociedade de classes, por meio da transformação social (SANTOS; PALUDO; OLIVEIRA, 2010).

Sendo assim, reportando-se às escolas do campo, é preciso que o professor domine o conteúdo escolar, que dialogue, respeite e dê atenção aos estudantes, que seja e ofereça condições de ser um sujeito ativo no processo de escolarização, organizando atividades que possibilitem a compreensão e a descoberta do mundo, porém sem Ihes negar explicações sobre conteúdos das bases matemáticas, do mundo das ciências, da área da linguagem, das artes, do estudo da sociedade. São esses conteúdos que todos necessitam para conquistar a cidadania na sociedade letrada. "[...] a Ciência pode estar sob controle da classe dominante, mas não é inútil (tanto que é difícil arrancá-la de seus circunstanciais proprietários). Ela resulta de uma produção cultural coletiva, cuja apropriação particularizada e restrita é uma situação a ser socialmente derrotada" (CORTELLA, 1999, p. 126).

O professor deve se sentir à vontade e seguro no papel que the cabe desempenhar.

Deve fazer das salas de aula espaços críticos que realmente ameacem a obviedade da cultura - isto é, a maneira como a realidade é usualmente construída - como uma coleção de verdades inalteradas e relações sociais imutáveis. Dentro de tais espaços críticos deve escavar os 'conhecimentos subjugados' daqueles que foram marginalizados e abandonados, cujas 
histórias de sofrimento e esperança raramente são tornadas públicas (McLAREN, 1997, p. 206).

Enfim, é preciso que o professor do campo mantenha-se mais avançado no processo de conhecer, que domine não só os conteúdos curriculares, mas que saiba, também, organizá-los e integrá-los; que saiba como proceder para transmitilos, de modo que os estudantes possam deles se apropriar; que esteja preparado para dar sentido a essa apropriação.

Torna-se também, imprescindível um currículo escolar do campo que contemple as relações com o trabalho na terra, que vincule a educação e a cultura, tornando-se um espaço de desenvolvimento para toda a comunidade. Estes currículos escolares do campo poderão constar questões relevantes para a sociedade atual, dentre elas, questões ambientais, agrária e fundiária, sociais, matrizes produtivas, econômicas, políticas, culturais, de gênero, de raça, etnia, sobre tecnologias na agricultura, entre outras.

Nesta perspectiva, não se pode esquecer do saber científico, que precisa ser articulado com o saber social a fim de contribuir para o desenvolvimento do campo. Nesta articulação, desde que ambos os saberes sejam considerados, reside a possibilidade de se fortalecer um projeto de desenvolvimento para o campo voltado para a emancipação do camponês. Para isto, torna-se necessário popularizar o conhecimento científico.

\begin{abstract}
Isto quer dizer estabelecer uma ponte real entre o conhecimento popular e o conhecimento acadêmico. Uma ponte que tem pelo menos duas vias: ${ }^{1}$, o acesso das organizações populares à ciência produzida historicamente pela humanidade, especialmente a que pode ajudar na solução dos seus problemas concretos; $2^{\mathrm{a}}$, a revisão da lógica de produção do conhecimento científico. De modo geral, a Academia não coloca como ponto de partida das pesquisas e da elaboração teórica a realidade da maioria da população. É preciso começar a produzir ciência a partir dos problemas do povo e para isso é preciso também preparar o povo para ser cientista. Garantir cientistas organicamente ligados às organizações populares (FUNDEP, 1994, p. 32).
\end{abstract}

Nessa direção, a educação do campo pode se tornar um importante instrumento para a produção de uma aguda reatualização da questão agrária, uma vez que para o enfrentamento da crise agrária existente provocada pela formação de 
uma forte agricultura capitalista, torna-se necessária a construção e a apropriação de saberes que ultrapassa o aprendido por tradição. Assim, no centro desse processo de reelaboração e construção do saber camponês, emerge o desafio de realizar uma efetiva articulação entre as práticas pedagógicas realizadas pela escola do campo e o saber social presente no campesinato. A integração/articulação entre essas extensões de saber permitirá ao camponês ultrapassar o senso comum e adquirir a consciência crítica. Fazendo uma interlocução com Freire (1987, p. 70-1), na leitura de sua Pedagogia do Oprimido, pode-se melhor compreender o que representa este processo na construção do saber camponês.

[...] certa vez, num dos 'círculos de cultura' do trabalho que se realiza no Chile, um camponês, a quem a concepção bancária classificaria de 'ignorante absoluto', declarou, enquanto discutia, através de uma 'codificação', o conceito antropológico de cultura. 'Descubro agora que não há mundo sem homem'. E quando o educador Ihe disse: 'Admitamos, absurdamente, que todos os homens do mundo morressem, mas ficasse a terra, os pássaros, os animais, os rios, o mar, as estrelas, não seria tudo isso mundo?' 'Não!', respondeu enfático, 'faltaria quem dissesse: Isto é mundo.' O camponês quis dizer, exatamente, que faltaria a consciência do mundo que, necessariamente, implica o mundo da consciência.

A educação do campo compreende o trabalho como produção da vida, base necessária para pensar a relação sociedade-natureza. É nesta totalidade que a relação educação e trabalho ganha significado e se diferencia da perspectiva do capital. Em síntese, o trabalho é compreendido como fator de humanização permanente, e é este o sentido que a Educação do Campo busca resgatar. (SANTOS; PALUDO; OLIVEIRA, 2010, p. 52).

O trabalho não é entendido como ocupação ou emprego, como mercadoria que se denomina força de trabalho. Ele é compreendido como uma relação social que determina o modo humano de existência, que, além de responder pela reprodução física de cada um, envolve as dimensões da cultura, lazer, social e artística.

\section{METODOLOGIA}


O trabalho foi produzido a partir de uma pesquisa qualitativa por meio de dois movimentos: a pesquisa bibliográfica, envolvendo aporte teórico de livros, leitura de artigos, materiais da internet e a análise de trabalhos das Reuniões Nacionais da Associação Nacional de Pesquisa em Educação - ANPED (da 33ํㅡ Reunião a 37ํㅜㄴ Reunião) que estão disponibilizadas na home page da instituição, relativas ao período de 2010 a 2015. Os trabalhos referente aos anos 2010 e 2011 constam na home page do Grupo - GT 03 (Movimentos Sociais e Educação) e nos anos de 2012 a 2015 do GT 03 (Movimentos Sociais, Sujeitos e Processos Educativos). Cada trabalho empreendido nesses GTs, num total de setenta e três, foram lidos e analisados na íntegra. Com a sistematização da análise, selecionou-se aqueles trabalhos que abordam a temática da educação do/no campo, o que perfizeram trinta e cinco trabalhos. Com esses dados e o envolvimento de referências de pesquisadores que estudam e investigam o universo da educação do/no campo, organizou-se este estudo.

\section{ANÁLISE DE RESULTADOS}

Dos trinta e cinco (35) textos selecionados, somente vinte e um (21) trataram especificamente a educação do campo enquanto uma articulação das lutas por políticas públicas específicas, lideradas especialmente por movimentos sociais, que visam a valorização daqueles que atuam no campo. Destes artigos, dezessete (17) amparam-se na resistência daqueles que ainda permanecem em seu meio, conservando seus costumes e características. E ainda três (3) abordam o estudo sobre a escola de famílias agrícolas. Neste mesmo contexto alguns artigos ainda explanam sobre a aprendizagem, infância, ensino no meio rural, escola multisseriada, educação especial, ensino superior e pedagogia do MST.

Do total, sete (7) elucidam sobre a organização escolar e as práticas educativas que ainda apresentam-se fragmentadas em disciplinas que não fazem relação com o mundo do trabalho interiorano, concordando com a falta de planejamento pedagógico e ratificando com as consequências sociais, tais como, o 
abandono da escola, a evasão, ou então o êxodo rural onde este jovem vai para o meio urbano em busca de escola e trabalho.

Em torno de quatro (4) artigos, esclarecem acerca da promoção de políticas públicas que incentivam e subsidiam os pequenos produtores rurais, de forma que os mesmos mantenham-se em seu meio.

Neste sentido, quatro (4) trabalhos do total, tratam a Reforma Agrária como forma de viabilizar a regionalização, também definida em outros quatro (4) artigos como assentamentos, três (3) como Pronera para promover ações educativas nos assentamentos.

Desde o ano de 2010 a 2015, do total, 10 escritores citaram estudos de caso, com resultados e necessidades pertinentes às regiões por eles analisadas. Somente um (1) estudou sobre a Pedagogia da Alternância, outros abordaram o assunto com leituras em torno do direito, igreja, via campesina, IDEB e agroecologia.

A educação do campo tem como desafio criar projetos educativos que permitam aos povos do campo o desenvolvimento sustentável e o crescimento social.

\section{CONSIDERAÇÕES FINAIS}

A educação é um processo formativo que permite outros olhares acerca das pessoas e do mundo. Refletir sobre a educação do campo é compreender o conjunto de transformações que a realidade vem exigindo das questões sociais, ambientais, políticas, culturais e econômicas. Para que ocorra tais transformações no contexto do campo é necessário pensar nas possibilidades de conhecer e vivenciar experiências diversas com várias formas de cultura.

Entendendo que a educação do campo envolve todo o contexto do campo e os saberes dos seus povos, ela faz sentido para revitalizar o campo de maneira que a educação se torne um agente de ligação com uma educação para todos. Conforme Brasil, MEC, (2003, p. 33):

A Educação do Campo pode ocorrer tanto em espaços escolares quanto fora deles. Envolve saberes, métodos, tempos e espaços físicos 
diferenciados. Se realiza na organização das comunidades e dos seus territórios que se distanciam de uma lógica meramente produtivista da terra e do seu próprio trabalho. Nas formas de organização se vivencia o direito de relacionar-se com a terra como cultura através dos diferentes conhecimentos e raízes históricas.

A educação do campo abrange a totalidade do campo e faz com que ele seja não só um lugar de produção e sim considerado o lar de famílias e um lugar repleto de cultura onde sua educação necessita ser tratada de forma diferenciada com relação à educação urbana. Para Caldart (2012, p. 259) a educação do campo, "[...] nomeia um fenômeno da realidade brasileira atual, protagonizado pelos trabalhadores do campo e suas organizações, que visa incidir sobre a política de educação desde os interesses sociais das comunidades camponesas". A autora evidencia que a educação do campo deve ter como protagonistas os trabalhadores do campo, pois desta forma todos os interesses das comunidades nas políticas de educação podem ser compreendidos conforme a necessidade do campo.

Portanto, a produção, a sobrevivência, a permanência, a valorização do campo, politização e outras questões socioculturais, bem como a valorização e preservação do meio ambiente e o desenvolvimento sustentável, são elementos essenciais na composição e estruturação do processo escolar do campo.

O desafio para a educação do campo será a construção da escola democrática e popular que trabalhe e assuma de fato a identidade do meio na qual está inserida, buscando desenvolver uma proposta de educação de qualidade voltada para as necessidades das populações campesinas aliada a um projeto de desenvolvimento territorial.

Para isso, é necessário que as pessoas envolvidas no trabalho educativo das escolas do campo sejam capazes de analisar, a um só tempo, a escola e a sua realidade social. Nessa análise é preciso considerar a realidade como construção do ser humano em cada época, em cada momento histórico. Sem considerar o ser humano, não tem sentido falar em realidade. O mundo que uma pessoa constrói é fortemente influenciado pelas concepções de mundo das demais pessoas com que esta pessoa vive, e pelas formas de conceber o mundo das pessoas que formam 0 


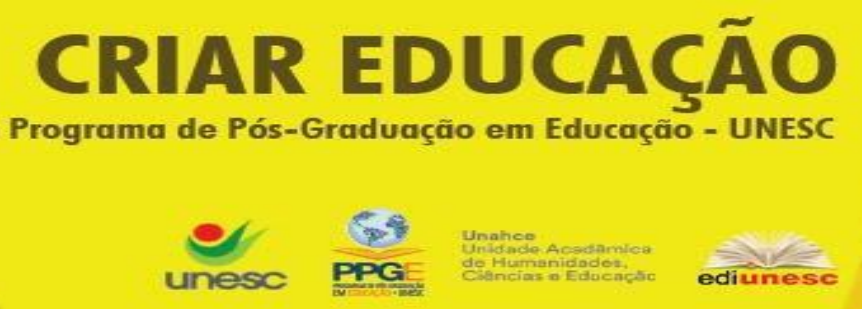

grupo social que esta pessoa faz parte.

Finalmente, cabe ainda considerar que todo esforço dispensado na transformação das escolas do campo deve contribuir para ampliar significativamente as oportunidades educacionais e o tempo de educação e de escolarização de todos os povos do campo e de mudar profundamente a escola onde este povo estuda. Para isso, é fundamental, como ponto de partida, que todas as pessoas envolvidas no trabalho cotidiano dessas escolas acreditem ser possível reorientar/reconstruir o seus currículos a partir das problemáticas que os cercam, não necessitando reproduzir modelos ou até mesmo seguir padrões disponíveis no mercado literário. O contexto da educação do campo abordado neste ensaio deve ser considerado como uma tentativa inicial que pretende provocar outras discussões necessárias para que a educação básica do campo obtenha o devido reconhecimento e que possa garantir a plena formação do homem e da mulher do campo.

\section{REFERÊNCIAS}

ARROYO, Miguel Gonsalez; CALDART, Roseli; CASTAGNA, Mônica (organizadores). FERNANDES, Bernado M.; CERIOLI; Paulo R.; CALDART, Roseli S. Primeira Conferência Nacional "Por Uma Educação Básica do Campo", 2004.

BRASIL. Ministério da Educação. Diretrizes operacionais para a educação básica nas escolas do campo: Resolução CNE/CEB, n. 1, de 3 de abril de 2002. Brasília. Disponível em: <http://portal.mec.gov.br/cne/arquivos/pdf/CEB012002.pdf>Acesso em: 13. Jan.2017.

. Lei 9.394, de 20 de dezembro de 1996. Estabelece as diretrizes e bases da educação nacional. Portal da Presidência da República. Disponível em: <https://www.planalto.gov.br/ccivil_03/Leis/L9394.htm>. Acesso em: 08 Jan.2017

. Lei 10.172, de 09 de janeiro de 2001. Plano Nacional de Educação PNE/Ministério da Educação. Brasília, DF: INEP, 2001. Disponível em:< http://www.planalto.gov.br/ccivil_03/leis/leis_2001//10172.htm> Acesso em: 19. Dez.2016.

. Referências para uma política nacional de educação do campo: caderno de subsídios / coordenação: Marise Nogueira Ramos, Telma Maria Moreira, Clarice Aparecida dos Santos. - Brasília: Secretaria de Educação Média e 


\section{CRIAR EDUCAÇÃO}

Revista do Programa de Pós-Graduação em Educação - UNESC

de Educação Continuada, Alfabetização e Diversidade (Secad/MEC), Cadernos Secad 2. Brasília, DF, 2007. Disponível em: < red-ler.org/educacaocampo.pdf .> Acesso em: 13. Jan. 2017.

IMBERNÓN, F. Formação docente e profissional: formar-se para a mudança e a incerteza. São Paulo: Cortez, 2000.

INCRA Instituto Nacional de Colonização e Reforma Agrária. Disponível em: $<$ WwW.incra.gov.br/ >Acesso em: 21.Jan.2017.

McLAREN, Peter. A vida nas escolas: uma introdução à pedagogia crítica nos fundamentos da educação. 2. ed. Porto Alegre (RS): Artes Médicas, 1997.

MST - Movimento dos Trabalhadores Rurais Sem Terra. Disponível em: $<$ www.mst.org.br/quem-somos/> Acesso em: 21.Jan.2017

SANTOS, Cláudio Eduardo Félix dos; PALUDO, Conceição; OLIVEIRA, Rafael Bastos Costa de. Concepção de educação do campo. In: Cadernos didáticos sobre educação no campo UFBA. Universidade Federal da Bahia. 2010. p. 13-65.

Recebido em julho 2017 Aprovado em fevereiro 2018 